\title{
JACQUES COPEAU E O ESPAÇO TEATRAL ${ }^{1}$
}

\author{
Juliano Farias Thomaz ${ }^{2}$, José Ronaldo Faleiro ${ }^{3}$
}

\section{PALAVRAS-CHAVE: Jacques Copeau, Teatro Francês, Espaço e Ética Teatral}

RESUMO: O presente artigo é integrante do projeto de pesquisa Poética, Ética e Estética na Pedagogia Teatral de Jacques Copeau - financiado pelo PROBIC/UDESC. E se propõe a pesquisar textos de Jacques Copeau ainda não disponíveis em Língua Portuguesa, bem como de outros autores que discutem sua obra, através das traduções do orientador Prof. Dr. José Ronaldo Faleiro. Assim, o presente artigo se atém às concepções estéticas presentes na obra de Copeau. O crítico de arte, ator e diretor-pedagogo foi um marco importante para a arte teatral. Desenvolveu diversas reformas poéticas, estéticas e éticas/morais para o teatro. Imbuído de indignação em relação ao que era produzido na França, dedicou a vida para renovar a produção cênica que o circundava. Concebeu em seu Teatro do Vieux Colombier e em sua Escola do Vieux Colombier um método de formação para atores visando a uma educação poética, técnica e, principalmente, moral. Sua proposta estética evidenciava o poeta e o texto, porém através da presença primordial do ator. Defendeu a renovação do teatro, entretanto, não apenas no estilo da representação e da encenação, mas também, uma renovação que buscava um "espírito novo" para a arte teatral. E para que essa renovação fosse possível era necessário um "palco nu", um palco para a ação dramática.

O presente artigo é integrante do projeto de pesquisa Poética, Ética e Estética na Pedagogia Teatral de Jacques Copeau - financiado pelo PROBIC/UDESC. E se propõe a pesquisar textos de Jacques Copeau ainda não disponíveis em Língua Portuguesa, bem como de outros autores que discutem sua obra, através das traduções do orientador Prof. Dr. José Ronaldo Faleiro.

Durante o período da pesquisa, foram lidas e analisadas as traduções inéditas, feitas pelo orientador em questão, de parte da obra de Jacques Copeau. De acordo com a estruturação do grupo de pesquisa, cada bolsista dedicou-se a estudar um enfoque específico dos textos ${ }^{4}$. No caso do autor deste projeto o foco inicial, no primeiro ano de pesquisa, apontou para as questões relativas ao conceito de Ética Teatral (2005-2006); em seguida, neste último ano, para as reflexões acerca do conceito de Espaço Teatral (2006-2007).

\footnotetext{
${ }_{1}^{1}$ Projeto de Pesquisa: " poética, ética e estética na pedagogia teatral de Jacques Copeau".

2 Bolsista do Projeto de Pesquisa "Poética, Ética e Estética na Pedagogia Teatral de Jacques Copeau”, financiado pelo PROBIC/UDESC

${ }^{3}$ Professor do Departamento de Artes Cênicas do CEART/UDESC e coordenador do projeto de pesquisa já citado.
} 
Neste ano de pesquisa o primeiro passo foi a releitura de toda a bibliografia já traduzida pelo orientador: primeiro com o intuito de reforçar o estudo do ano anterior; e também como revisão das traduções do orientador para uma futura publicação. A etapa seguinte foi estudar a biografia de Copeau, assim como o contexto histórico/social no qual se integrava sua obra com foco nas questões cênico-espaciais. identificando textos e trechos que tratam deste tema.

Dando continuidade a esta trajetória, o autor deste artigo tem como objetivo final concluir este estudo através da elaboração de uma monografia. A proposta é desenvolver um TCC para analisar a evolução do conceito de Espaço Teatral desenvolvido e aplicado pelo encenador-pedagogo no seu Teatro do Vieux-Colombier ${ }^{5}$, durante a primeira metade do século XX. Além disso, busca ainda propor uma sistematização das influências recebidas por Copeau, bem como as contribuições espaciais para o teatro subseqüente.

\section{UM ESPAÇO PARA A AÇÃO DRAMÁTICA}

Jacques Copeau [1879-1948] foi crítico de arte, ator e diretor-pedagogo. Viveu do final do século XIX até meados do século XX. Francês, desenvolveu boa parte de sua obra em Paris, durante um período de diversas transformações tanto artísticas, quanto sociais e políticas. Os conflitos políticos entre socialistas e capitalistas eram destaque na capital francesa. Do mesmo modo, e, em certa medida, consequentemente, abrigava conflitos de ordem estética entre as diversas correntes da época: naturalismo, simbolismo, futurismo e surrealismo. A produção artística em todos os gêneros está pautada pelo gosto burguês, mas é a arte teatral o meio para propagar e manter a ideologia burguesa.

O teatro, por ser a arte das massas, é tratado com maior rigor do que os outros gêneros, exatamente como o cinema está sujeito às restrições que não se aplicam ao teatro. A partir do meio do século [XIX] e de acôrdo com as intenções do Govêrno, os esforços dos dramaturgos concentram-se na criação de um instrumento de propaganda da ideologia da burguesia, dos seus princípios econômicos, socais e morais. A sêde de divertimento das classes dos governantes, o seu fraco pelas distrações públicas, o seu prazer em ver e serem vistas fazem do teatro a arte representativa da época. Jamais nenhuma sociedade se deliciaria a tal ponto com o teatro. 6

\footnotetext{
${ }^{\overline{4}}$ Mariana Godinho dedicou-se à Dramaturgia, Luciana Holanda à relação Ator\&Ética, Julie Knabben ao Espaço , Mariana Schmitz à Pedagogia e Paula Farias ao Teatro Popular.

${ }^{5}$ Théâtre du Vieux-Colombier - Teatro do Vieux-Colombier (1913-14 França; 1917-19 EUA; 1919-24 França): Teatro criado por Jacques Copeau inaugurado no ano de 1913 que colaborou para diversas reformações da cena francesa do início do século XX. Neste teatro Copeu formou diversos artistas reconhecidos pela crítica da época e subseqüente. Tais como: Louis Jouvet (1887 - 1951), Charles Dullin (1885 - 1949), Suzanne Bing (1885 - 1967).
} 
Copeau foi um marco importante para a arte teatral. Desenvolveu com muito trabalho diversas reflexões acerca do teatro. Imbuído de indignação em relação ao que era produzido na cena francesa, dedicou a vida para renovar a produção cênica que o circundava. Concebeu em seu Teatro do Vieux Colombier e em sua Escola do Vieux Colombier um método de formação para atores $^{7}$ visando a uma educação poética, técnica e, principalmente, moral. Para Copeau, o ator deve ter conhecimento e domínio tanto literário, quanto técnico. Entretanto, antes disso deveria formar-se moralmente, tornar-se um ser humano. Como declara: "Que o ator volte a ser um ser humano, e todas as grandes transformações no teatro decorrerão dá1". ${ }^{8}$ Sentia a necessidade de novas formas de conduta para os profissionais do teatro, buscando uma dedicação incondicional, uma disciplina rigorosa, e um domínio técnico exemplar.

Suas reflexões se iniciaram durante a época que Copeau foi crítico literário e dramático, quando também se dedicou ao estudo técnico e histórico do teatro. Neste período alimentou sua indignação em relação à produção teatral, que se originou através da influência primeira de dois grandes mestres: Constantin Stanislavski e André Antoine.

O primeiro, o encenador russo Stanislavski, influenciou a partir do período em que nega a sobreposição do encenador em relação ao ator, do mesmo modo que não dá mais valor ao cenário; busca uma "emoção verdadeira" para o ator futuro; e clama a todos a sair do teatro e partir para os campos. Copeau explica:

\begin{abstract}
Daí [1906] em diante, em sua narrativa, o eu vai substituir o nós, que ele empregava com tanto amor. (...) Ele já não dá crédito à dominação do encenador sobre o intérprete. Também não dá crédito à prestígios da decoração cênica. Reivindica um tablado nu para o ator soberano. Concentra sua única preocupação, e seu recurso, a sua esperança, no desenvolvimento futuro do ator, não como instrumento, mas como fonte criadora da vida artística, de emoção verdadeira. O que ele busca são as leis profundas de uma disposição criadora no ator, "a condição favorável à aparição de uma inspiração por meio da vontade"... (...) Constantin Stanislavski apela para os jovens, para os alunos, para os figurantes, para sair do teatro, se instalar nos campos, formar o núcleo de uma comunidade nova, de uma confraria de atores, e recomeçar tudo.
\end{abstract}

O segundo, Antoine, foi um importante incentivador do trabalho de Copeau logo no princípio do Vieux Colombier. Influenciou principalmente do ponto de vista da dedicação,

\footnotetext{
${ }^{6}$ HAUSER, Arnold, A História Social da Literatura e da Arte. Tomo II. São Paulo: Ed. Mestre Jou, 1980-1982 - Trad. De Walter H. Geenen, p.970.

7 Ver FALEIRO, José R. A Formação do Ator a partir dos Cadernos de Teatro de Léon Chancerel e dos Cadernos de Teatro do Tablado; A Escola do Vieux Colombier. IN: O Teatro Transcende; e SCHMITZ, M. A VOCAÇÃO PEDAGÓGICA EM JACQUES COPEAU: L'ÉCOLE DU VIEUX COLOMBIER (1920-1924).

8 COPEAU, J. The Spirit in the Little Theatres. In: Registros I, Apelos. Textos coletados e estabelecidos por MarieHélène Dastè e Suzanne Maistre Saint-Denis. Notas de Claude Sicard. Paris: Guillimard, 1974, p. 120-130 - Trad. de José Ronaldo Faleiro, p.4.
} 
disciplina e da abnegação pela arte teatral, bem como acerca da idéia de se valorizar os jovens para alcançar uma renovação.

(...) ele se dignou a recomendar-lhes - ou, se não a lhes recomendar, pelo menos a thes indicar - o nosso empreendimento, o que, para nós, meros principiantes, equivalia a um verdadeiro batismo. Lembro o quanto fiquei comovido, grato por essa generosidade. Ele nos levava a sério. Encorajava seriamente aqueles que o haviam seguido a prestar atenção em nós. E esse pequeno discurso terminava com uma exortação que não era sem mérito na boca de um velho leão ferido: $\square \square$ Só tenho uma coisa a lhes aconselhar $\square \square$ - nos dizia ele - $\square \square$ mais $\boldsymbol{u}$ menos o que Henri Becque nos aconselhava a nós mesmos, quando começamos: Avante juventude, e passem por cima de nosso corpo!. 9

Assim, seguindo seus mestres e se opondo, desde a abertura do Vieux Colombier (1913), a todos os exibicionismos que povoavam a cena parisiense, manifestou veemente sua indignação em relação à produção teatral da época. E foi justamente essa indignação que o impulsionou a lutar por uma renovação dramática: “[...] se quiserem que designemos com mais clareza o sentimento que nos anima, a paixão que nos impele, nos subjuga, nos obriga, à qual devemos por fim ceder: é a indignação". ${ }^{10}$

\footnotetext{
Uma industrialização desenfreada que, dia a dia mais cinicamente, degrada a nossa cena francesa e desvia dela o público cultivado; a monopolização da maior parte dos teatros por um punhado de farsantes a soldo de comerciantes sem vergonha; por toda a parte, e até onde grandes tradições deveriam salvaguardar algum pudor, o mesmo espírito de cabotinismo e de especulação, a mesma baixeza; por toda a parte o blefe, o exagero de todo o tipo e o exibicionismo de toda a natureza parasitando uma arte que está morrendo, e que já nem sequer é discutida; por toda parte apatia, desordem, indisciplina, ignorância e imbecilidade, desdém do criador, ódio da beleza; uma produção cada vez mais louca e vã, uma crítica cada vez mais indulgente, um gosto cada vez mais perdido: eis o que nos indigna e nos revolta. ${ }^{11}$
}

Copeau iria combater justamente com o que considerava como duas "doenças" do teatro: "industrialismo" e o "cabotinismo". O "industrialismo" seria o domínio, que se instalava na França, de um teatro comercial que visava lucro e pouco se dedicava a criação poética e artística. Sua falta de técnica, sua indiferença em relação à beleza, sua indisciplina, seus exageros, sua ambição financeira... Revoltava JC. ${ }^{12}$

O "cabotinismo" seria tudo aquilo que acreditava não poder existir no verdadeiro ator: exageros, espírito exibicionista, falta de treinamento, fraqueza de emoções, pouca dedicação, má

${ }^{9}$ COPEAU, J. André Antoine. In: Registres I. Appels. P. 69-73. Paris: Gallimard, 1974. - Tradução José Ronaldo Faleiro. p. 3.

${ }^{10}$ Idem. Uma Tentativa de Renovação Dramática. In: Registres I. Appels. P. 19-32. Paris: Gallimard, 1974. -

Tradução José Ronaldo Faleiro. p. 1.

${ }^{11}$ Ibidem, p. 1-2.

${ }^{12}$ COPEAU, J. The spirit in the little theatres. In: Registres I. Appels. P. 120-130. Paris: Gallimard, 1974. -

Tradução José Ronaldo Faleiro. p. 2. 
conduta, entre outros. Apoiado no "industrialismo", o "cabotinismo" era "[...] a doença da insinceridade, ou antes da falsidade. Quem foi atingido por ela deixa de ser um indivíduo autêntico, deixa de ser um ser humano""13.

Ambicionando uma renovação, Copeau desenvolve, em seu Teatro e, principalmente, em sua École (1913-1924), novas concepções de educação e preparação do ator buscando uma formação completa. Através da disciplina, da dedicação, do aprimoramento da técnica, do conhecimento dramático e poético e principalmente de uma formação moral. Sentia a necessidade de dar a seus atores e alunos uma cultura geral que possibilitasse a busca por qualidades humanas e dignidade de artistas.

Seria necessário fazer brotar no teatro um espírito de luta contra o "industrialismo" e o "cabotinismo". Um espírito que reergueria a arte dramática; que lhe devolveria o seu valor. Pautado pelo respeito e pela dedicação ao "ofício do teatro".

\begin{abstract}
Sejam quais forem os desejos e as aspirações de vocês, seja qual for a carreira que vocês se propõem a seguir, seja qual for a técnica que vocês têm a intenção de dominar, antes de tudo tratem de ser homens. Não se deixem dessecar, nem corromper, mas pela vontade apliquem-se para fazer reinar em seu caráter uma bela, uma sólida, uma sorridente, valente e flexível harmonia humana. Vejam, meus amigos, importa sobretudo, importa unicamente, no meio de uma confusão dessas, fazer um pacto com a própria alma. E ater-se lealmente a ele. ${ }^{14}$
\end{abstract}

Sua proposta estética evidenciava o poeta e o texto, porém através da presença primordial do ator. Sua concepção de treinamento e, posteriormente, sua metodologia de formação de atores, estavam pautadas em buscar uma nova tendência estética - a recusa do naturalismo. Defendeu uma renovação que buscava um "espírito novo"15 para a arte teatral. E para que essa renovação fosse possível era necessário um ator novo, renovado, com uma formação baseada em novas idéias filosóficas.

É, porém, a naturalidade, e não o naturalismo, que Copeau desejava no teatro. É por
causa dessa idéia que ele sempre gostou de levar os seus atores para o campo, a fim de
preparar os seus jogos. Tais excursões tinham como base a sua formação filosófica. As
idéias de Bergson estavam muito em voga naquele tempo. Copeau tentava preencher a
sua própria vida com «o élan vital» do filósofo, optar pelo intuitivo, contra o
empirismo e o racionalismo. Portanto, para ele, a chave ainda era a personalidade do
ator, utilizada não por razões narcisistas, mas a serviço de uma idéia do progresso
humano. Para ele, esse progresso não seria baseado no Darwinismo e no mecanicismo
científico do século XIX, mas na passagem, no século XX, para uma evolução
espiritual e criativa de uma geração a outra. 16

Td. Ibid. p. 3.

${ }^{14}$ COPEAU, J. Apelos. In: Registres I. Appels. P. 105-112. Paris: Gallimard, 1974. - Tradução José Ronaldo Faleiro. p. 2.

${ }^{15}$ Ver COPEAU, J. The Spirit in the Little Theatres. In: Registros I, Apelos e Apelos. In: Registres I. Appels.

16 RUDLIN, J. Copeau e a juventude: a formação do ator. In: Copeau l’Éveilleur «La Cerisaie »/Lectoure: Bouffonneries, 1995. n 34. p. 104-115. - Tradução de José Ronaldo Faleiro. p. 05- 06. 
Como Marvin Carlson explica: “[...] ele [Copeau] preconiza uma simplicidade estrema no cenário físico, o famoso tréteau nu (palco nu), que permitiria ao ator e ao autor apresentar o texto sem intrusão "teatral'" ${ }^{17}$ Suas contribuições acerca da questão referente ao Espaço foram de grande relevância para a essa linha estética que evidenciava o ator e a poesia. Em suas reflexões no tocante cênico-espacial defendia que o texto e os cenários deveriam, como os demais elementos da cena, estar a serviço do "criador dramático":

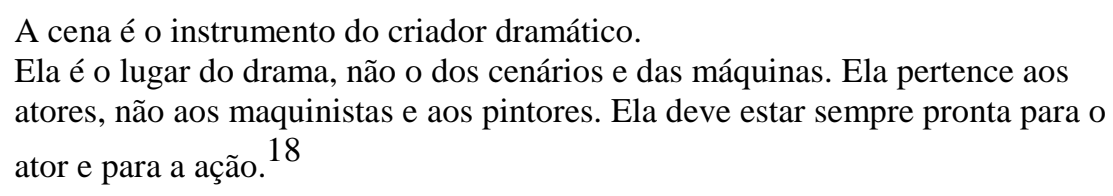

Para Copeau, somente através da doação total a seu "ofício" que os profissionais do teatro conquistariam a real renovação do teatro. Porém antes de atingirem o aprimoramento técnico era necessário conhecer-se; ser um Homem ${ }^{19}$, doar-se. Sempre buscando a perfeição poética, respeitando o lugar do poeta (sempre em busca da criação) presente no drama. E sempre procurando destacar que "a cena é o instrumento do criador dramático", e que é a ele que todos devem servir: "Ali onde ele [o ator] é escravo, é necessário que seja o mestre. Pois ele é o único mestre. E, sem ele, o teatro está hoje sem mestre". ${ }^{20}$

No entanto, para isso era necessário reivindicar a retirada de todo e qualquer cenário desnecessário, deixar somente um "palco nu” evidenciando as ações do ator.

\begin{abstract}
Quanto mais a cena for nua, mais a ação poderá fazer com que nasçam prodígios sobre ela. Quanto mais for austera e rígida, tanto mais a imaginação joga livremente.

É na restrição material que a liberdade de espírito se apóia. Sobre a cena árida o ator é encarregado de realizar tudo, de tirar tudo de si mesmo.

O problema do ator, do jogo, do movimento íntimo à obra, da interpretação pura, é assim formulado em toda a sua amplitude.
\end{abstract}

Um tablado nu e atores de verdade. ${ }^{21}$

\footnotetext{
${ }^{17}$ CARLSON, Marvin. Teorias de Teatro: Estudo histórico-crítico, dos gregos à atualidade. São Paulo: Fundação Editora da UNESP, 1997 - Trad. de Gilson César Cardoso de Souza, p. 329-330.

${ }^{18}$ COPEAU, J. Aos Atores. In: Registres I. Appels. P. 203-215. Paris: Gallimard, 1974. - Tradução José Ronaldo Faleiro. p. 7.

${ }^{19}$ Homem é aplicado aqui no sentido de Ser Humano e não se referindo a questões de gênero.

${ }^{20}$ Ibidem, p. 8.

${ }^{21}$ COPEAU, J. A Cena. In: Registres I. Appels. P. 217-226. Paris: Gallimard, 1974. - Tradução José Ronaldo Faleiro. p. 2.
} 
Portanto, todas as reflexões e concepções de Copeau para arte teatral visavam um só propósito: revitalizar uma arte que acreditava estar “[...] empobrecida, diminuída, cansada, desacreditada", uma arte que se perdia em um comercialismo. Assim, desenvolveu suas teorias que hoje são vistas isoladamente, mas que foram concebidas como um todo único, a partir de uma ambição especifica: devolver ao teatro a verdadeira arte do ator; e, ao ator, a consciência humana.

\begin{abstract}
No dia em que eu sentir o meu pé fraquejar em cena, no dia em que me faltar voz, em que eu me retirar para viver entre essas três colinas de onde a vista se estende até a linha do Jura, eu gostaria que nesse momento algo em mim ainda continuasse a correr o mundo, algo mais robusto, mais jovem e maior do que eu, algo de que me fosse permitido dizer: foi para isso que eu trabalhei ${ }^{22}$
\end{abstract}

\title{
BIBLIOGRAFIA
}

CARLSON, Marvin. Teorias de Teatro: Estudo histórico-crítico, dos gregos à atualidade. Trad. de Gilson César Cardoso de Souza. São Paulo: Fundação Editora da UNESP, 1997.

COPEAU, Jacques. Un Essai de Rénovation Dramatique [Uma Tentativa de Renovação Dramática]. In: Registres I; Appels [Registros I; Apelos]. Textes recueillis et établis par MarieHélène Dasté et Suzanne Maistre Saint-Denis. Notes de Claude Sicard. [Textos coletados e estabelecidos por Marie-Hélène Dasté e Suzanne Maistre Saint-Denis. Notas de Claude Sicard]. Paris: Gallimard, 1974. p. 19-32. - Trad. de José Ronaldo Faleiro

. Appels [Apelos]. In: Registres I; Appels [Registros I; Apelos]. Textes recueillis et établis par Marie-Hélène Dasté et Suzanne Maistre Saint-Denis. Notes de Claude Sicard. [Textos coletados e estabelecidos por Marie-Hélène Dasté e Suzanne Maistre Saint-Denis. Notas de Claude Sicard]. Paris: Gallimard, 1974. p. 105-112. - Trad. de José Ronaldo Faleiro.

The Spirit in the Little Theatres. In: Registres I; Appels [Registros I; Apelos]. Textes recueillis et établis par Marie-Hélène Dasté et Suzanne Maistre Saint-Denis. Notes de Claude Sicard. [Textos coletados e estabelecidos por Marie-Hélène Dasté e Suzanne Maistre Saint-Denis. Notas de Claude Sicard]. Paris: Gallimard, 1974. p. 120-130 - Trad. de José Ronaldo Faleiro.

. Aux acteurs [Aos Atores]. In: Registres I; Appels [Registros I; Apelos]. Textes recueillis et établis par Marie-Hélène Dasté et Suzanne Maistre Saint-Denis. Notes de Claude Sicard. [Textos coletados e estabelecidos por Marie-Hélène Dasté e Suzanne Maistre SaintDenis. Notas de Claude Sicard]. Paris: Gallimard, 1974. p. 203- 215 - Tradução José Ronaldo Faleiro.

22 In: SICARD, C. Jacques Copeau e a Escola do Vieux Colombier. In: Copeau l'Eveilleur. p. 116-126 - Trad. José Ronaldo Faleiro. p. 09. 
. A Cena. In: Registres I; Appels [Registros I; Apelos]. Textes recueillis et établis par Marie-Hélène Dasté et Suzanne Maistre Saint-Denis. Notes de Claude Sicard. [Textos coletados e estabelecidos por Marie-Hélène Dasté e Suzanne Maistre Saint-Denis. Notas de Claude Sicard]. Paris: Gallimard, 1974. p. 217-226 - Tradução José Ronaldo Faleiro.

ECO, Umberto. Como se faz uma tese. São Paulo: Ed. Perspectiva, 1989.

FALEIRO, José R. A Formação do Ator a partir dos Cadernos de Teatro de Léon Chancerel e dos Cadernos de Teatro do Tablado. Tese do Doutorado - Université de Paris X - Nanterre: 1998. Trad. José Ronaldo Faleiro

. A Escola do Vieux Colombier. IN: O Teatro Transcende. v. 08 p. 19-32, Blumenau: FURB, 1999.

. Poética, Ética e Estética na Pedagogia Teatral de Jacques Copeau.

[Projeto de Iniciação Científica - 2005-2007] Universidade do Estado de Santa Catarina/Centro de Artes - Florianópolis: 2005.

HAUSER, Arnold, A História Social da Literatura e da Arte. Trad. De Walter H. Geenen. Tomo II. São Paulo: Ed. Mestre Jou, 1980-1982

RUDLIN, J. Copeau e a juventude: a formação do ator. IN: Copeau l'Éveilleur [Copeau, Aquele que Desperta]. Textos reunidos por Patrice PAVIS e Jean-Marie THOMASSEAU. «La Cerisaie »/Lectoure: Bouffonneries, 1995. n 34. p. 104-115. - Trad. de José Ronaldo Faleiro.

SALOMON, D. V. Como fazer uma monografia. 11 a ed. São Paulo: Martins Fontes, 2001.

SCHMITZ, Mariana da S.. A VOCAÇÃO PEDAGÓGICA EM JACQUES COPEAU: $L$ 'ÉCOLE DU VIEUX COLOMBIER (1920-1924). [Trabalho de Conclusão de Curso] Universidade do Estado de Santa Catarina/Centro de Artes - Florianópolis: 2006.

SICARD, Claude. Jacques Copeau et l'École du Vieux Colombier. [Jacques Copeau e a Escola do Vieux Colombier]. IN: Copeau l'Éveilleur [Copeau, Aquele que Desperta]. Textos reunidos por Patrice PAVIS e Jean-Marie THOMASSEAU. «La Cerisaie »/Lectoure: Bouffonneries, 1995. p. 116-126. - Trad. de José Ronaldo Faleiro. 